\title{
Ordinal Variables in the Segmentation of Advertisement Receivers
}

\author{
Marek Walesiak, Józef Dziechciarz, Andrzej Bak \\ Wroclaw University of Economics, \\ Komandorska 118/120, 53-345 Wroclaw, Poland
}

\begin{abstract}
The paper presents segmentation study, which employs methods of classification to single out the segments. The variables measured on the ordinal scale were used as the criteria of market segmentation. Variables used reflected students' attitude towards 20 statements about advertising. Ordinal character of the data required application of specific measure (1) of object's distance. This measure was used in order to evaluate the similarities of objects, which were based on numbers of relations "equal to", "greater than" and "smaller than".
\end{abstract}

Keywords: Classification, Measurement Scales, Market Segmentation.

\section{Market segmentation}

Pioneer article of Smith [1956] caused that segmentation appeared as widely researched and applied attitude to marketing. Almost each enterprise observes heterogeneity of its market - that is why the division of consumers into homogeneous sub-groups seems to be promising approach. Due to that fact enterprise may expect increase of profitability of its market operations. Theoretical justification of what had been expected, was published in the work of Frank, Massey and Wind [1972]. They proved that the expected value of obtained profitability level is higher with the diversified approach to the market. This caused quick acceptance of segmentation by both managers and specialists of marketing research.

Marketing strategies are constructed on the results of the undertaken segmentation. Similar tendencies are observed in Poland. Multinationals which operate on Polish market appreciate the role of diversification of marketing strategies according to identified market segments more than the others.

There are two most frequently employed attitudes towards segmentation of practical market researches (see Green [1977]):

- segmentation a priori,

- segmentation post hoc based on classification procedures.

In a post hoc model of segmentation - where classification methods are used differs from the a priori model only by the way the base variable was chosen for segmentation. Instead of arbitrary choice of segmentation base (in the a priori approach), a variety of consumers characteristics are used in the post hoc ap- 
proach. Additionally, in the next step the classification procedure where neither number of classes nor their descriptive characteristics are known is used. The most frequently used variables for the segmentation study are those identifying needs, attitudes, lifestyle and psychographic characteristics of the consumers. As the result homogeneous consumer groups are isolated and identified. Factor analysis, which aims at reducing the set (number) of diagnostic features often, precedes class isolation process.

The authors of overviewing works by Frank and Green [1968], Saunders [1980], Punj and Stewart [1983], Beane and Ennis [1987] and Arabie and Hubert [1996] pointed out main application fields for classification methods in marketing, mainly in market segmentation.

Empirical segmentation studies, which have been dominated by two mentioned above approaches ( $a$ priori and post hoc), are supplemented by fuzzy and stochastic classification, regression analysis, and conjoint analysis.

Application of classification methods requires formalisation of the "similarity of objects" term. The use of particular construction of similarity measure depends on the scale on which the variables were measured. The choice similarity measures is easy when all the variables describing examined objects are measured on one type of scale. Literature presents plenty of different ways of similarity measurement which can be adopted to variables measured on scale: ratio, interval and (or) ratio, nominal (including binary variables). Wide range of similarity measures has been shown in the works of: Cormack [1971]; Anderberg [1973]; Everitt [1974]; Kaufman and Rousseeuw [1990].

Walesiak [1993], p. 44-45, gives the proposal of the new measure of objects similarity, which can be applied in situation when variables describing those objects are measured only on the ordinal scale. In the construction of the measure under consideration, Kendall's idea of correlation coefficient $\tau$ for ordinal variables (see Kendall [1955], p. 19), was used. There is given non-empty set $A$ of objects, each of them is described by $m$ ordinal variables. Because of the fact that on the ordinal scale the only possible empirical operation is counting of events (which means: allotting the number of relations "equal to", "greater than" and "smaller than"), construction of distance measure in the following form is being proposed:

$$
d_{i k}=\frac{1}{2}-\frac{\sum_{j=1}^{m} a_{i k j} b_{k i j}+\sum_{j=1}^{m} \sum_{\substack{l=1 \\ l \neq i, k}}^{n} a_{i l j} b_{k l j}}{2\left[\left(\sum_{j=1}^{m} a_{i k j}^{2}+\sum_{j=1}^{m} \sum_{l=1}^{n} a_{i l j}^{2}\right)\left(\sum_{\substack{j=i, k \\ j}}^{m} b_{k i j}^{2}+\sum_{j=1}^{m} \sum_{\substack{l=1 \\ l \neq i, k}}^{n} b_{k l j}^{2}\right)\right]^{\frac{1}{2}}},
$$


where:

$$
\begin{aligned}
& a_{i p j}\left(b_{k r j}\right)=\left\{\begin{array}{cc}
1, & \text { if } x_{i j}>x_{p j}\left(x_{k j}>x_{r j}\right) \\
0, & \text { if } x_{i j}=x_{p j}\left(x_{k j}=x_{r j}\right), \\
-1, & \text { if } x_{i j}<x_{p j}\left(x_{k j}<x_{r j}\right)
\end{array}\right. \\
& \begin{array}{c}
p=k, l ; r=i, l ; i, k, l=1, \ldots, n-\text { number of object, } \\
j=1, \ldots, m-\text { number of ordinal variable, }
\end{array} \\
& x_{i j}\left(x_{k j}, x_{l j}\right)-i \text {-th }(k-\text { th, } l \text {-th) observation on } j \text {-th ordinal variable, } \\
& \sum_{j=1}^{m} a_{i k j}^{2}+\sum_{j=1}^{m} \sum_{l=1}^{n} a_{i l j}^{2} \quad-\quad \text { number of relations "greater than" and } \\
& l \neq i, k
\end{aligned}
$$

A distance measure $d_{i k}$ satisfies conditions: $d_{i k} \geq 0, d_{i i}=0, d_{i k}=d_{k i}$ (for all $i, k=1, \ldots, n)$ and does not always satisfy the triangle inequality (based on simulation analysis). Transformation of ordinal data by any strictly increasing function does not change the value of distance (1).

Distance $d_{i k}$ assumes values from the $[0 ; 1]$ interval. Value 0 indicates that for the compared objects $i, k$ between corresponding observations of ordinal variables, only relations "equal to" take place. Value 1 indicates that for the compared objects $i, k$ between corresponding observations on ordinal variables, relation "greater than" take place or relation "greater than" and relations "equal to" if they are hold for other objects (i.e. objects numbered $l=1, \ldots, n$; where $l \neq i, k)$.

Discussion about choice of hierarchical classification methods has been shown in the work of Gordon [1987]. In marketing and other behavioural sciences, the most popular hierarchical agglomerative method is complete linkage (see Arabie and Hubert [1994], p. 171). The method of complete linkage has been adopted for the segmentation. This method appears as one of hierarchical agglomerative methods which doesn't show the tendency to create the classes of chain. Method of complete linkage avoids the disadvantage of other hierarchical methods which show the tendency to incorporate the new objects into the existing groups. New classes are rarely established. As the result, the possibility of presence of dissimilar objects in one class occurs. The distance given by the formula (1) has been adopted as the similarity measure. 


\section{Segmentation of advertising responders - case study}

A group of 244 students of Wroclaw University of Economics were questioned in order to isolate the groups (segments) which similarly reacted to certain statements about advertisements. The experiment has been conducted with the plan to use the classification methods (a post hoc approach). The questionnaires were done in the 1996/1997 academic year. Segmentation was based on 20 statements about advertising:

1. Information coming from the advertisement helps me to make a decision.

2. I don't believe such an advertisement which emphasises higher product quality than its competitors.

3. I usually decide to buy advertised product which is accompanied by additional bonuses.

4. Without advertisements no product can be accepted by wide range of consumers.

5. In-store promotion has limited influence on my purchasing decision.

6. Advertising is a good source of information.

7. Advertising tempts people to spend their money foolishly.

8. If advertising were stopped, the customer would be better off.

9. Generally advertisements annoy me.

10. The most effective are TV commercials.

11. On the whole, advertising is believable.

12. I enjoy television commercials.

13. In my opinion advertisements stronger the decision of purchases of elderly people.

14. Information of advertised products saves my precious time.

15. I usually decide to buy newly launched and advertised product.

16. I think, that legal regulations are necessary to limit the advertisement influence on consumers.

17. My brand loyalty could not be changed even by exceptionally good advertisement of competitive brands.

18. Most of the advertisements are based on the credulity of consumers.

19. Before purchasing of newly advertised product I usually seek for my friends' advice.

20. Advertisement is a sign for me that the product should not be purchased.

The questioned students were asked to mark the category on the five-degree ordinal scale, which reflected their attitude towards the given statement: 5 Strongly agree; 4 - Agree; 3 - Neither agree nor disagree; 2 - Disagree; 1 Strongly disagree.

For the purpose of this study, the hierarchical agglomerative methods were used to classify students into relatively homogeneous clusters. The complete linkage method proved to be most suitable, because it avoids chain effect. Distance (1) was assumed as the measure of similarity of objects. The optimal number of segments should be between 10 and 5. Due to the fact that the last 
class has too few objects to consider it a segment, finally seven segments have been established.

In a post hoc segmentation, very often the respondents attitudes measured on the Likert scale is used as the segmentation base. In order to establish segments profiles the additional respondents characteristics are analysed (see Green, Tull and Albaum [1988], p. 691-693). The chosen demographic, geographic and economic characteristics are presented in the Table 1.

Table 1: Characteristics of market segments

\begin{tabular}{|c|c|c|c|c|c|c|c|c|}
\hline \multirow{2}{*}{\multicolumn{2}{|c|}{ Variables }} & \multicolumn{7}{|c|}{ Segments } \\
\hline & & $\bar{I}$ & $\overline{\text { II }}$ & III & IV & $\overline{\mathrm{V}}$ & $\overline{\mathrm{VI}}$ & VII \\
\hline \multicolumn{2}{|l|}{ Sex (female / male) } & $20 / 25$ & $27 / 19$ & $22 / 11$ & $9 / 14$ & $6 / 11$ & $29 / 24$ & $13 / 12$ \\
\hline \multicolumn{2}{|l|}{$\begin{array}{c}\text { Average number } \\
\text { of household members }\end{array}$} & 3.82 & 3.67 & 3.85 & 3.70 & 3.94 & 3.70 & 3.60 \\
\hline \multicolumn{2}{|l|}{$\begin{array}{l}\text { Average time devoted daily } \\
\text { for TV watching (in hours) }\end{array}$} & 1.67 & 1.51 & 1.87 & 1.58 & 1.89 & 1.15 & 1.67 \\
\hline \multicolumn{2}{|l|}{$\begin{array}{l}\text { Average time devoted daily } \\
\text { for radio listening (in hours) }\end{array}$} & 3.20 & 4.04 & 4.32 & 3.02 & 3.35 & 3.07 & 3.58 \\
\hline \multicolumn{2}{|c|}{$\begin{array}{l}\text { Median of monthly income being at } \\
\text { student's disposal (in Polish Zlotys) }\end{array}$} & 184.4 & 143.8 & 129.7 & 158.3 & 175.0 & 182.5 & 155.0 \\
\hline \multirow{4}{*}{$\begin{array}{l}\text { Place of residence during studies } \\
\text { (\% of students) }\end{array}$} & 1 & 51.1 & 47.8 & 33.3 & 30.4 & 41.2 & 32.1 & 36.0 \\
\hline & 2 & 35.6 & 28.3 & 48.5 & 39.1 & 41.2 & 43.4 & 24.0 \\
\hline & 3 & 4.4 & 6.5 & 3.0 & 4.3 & 5.9 & 13.2 & 12.0 \\
\hline & 4 & 8.9 & 17.4 & 15.2 & 26.1 & 11.8 & 11.3 & 28.0 \\
\hline \multirow{4}{*}{$\begin{array}{l}\text { Permanent place of residence } \\
\text { (\% of students) }\end{array}$} & $\mathrm{A}$ & 62.2 & 39.1 & 57.6 & 43.5 & 35.3 & 52.8 & 40.0 \\
\hline & B & 6.7 & 17.4 & 6.1 & 4.3 & 0.0 & 18.9 & 24.0 \\
\hline & $\mathrm{C}$ & 20.0 & 32.6 & 27.3 & 34.8 & 41.2 & 20.8 & 24.0 \\
\hline & D & 11.1 & 10.9 & 9.1 & 17.4 & 23.5 & 7.5 & 12.0 \\
\hline
\end{tabular}

Key:

1 - student's hostel

2 - parents' flat

A - town with more than 100,000 inhabitants

3 - own flat

4 - rented room

$\mathrm{B}$ - town with 50,000 to 100,000 inhabitants

C - town with less than 50,000 inhabitants

$\mathrm{D}$ - village

Segment I treats advertisement as a source of potential benefits. Advertisement for them is an information source of the product and supports their decision of purchasing. It is dominated by women (80\%) mainly been accommodated at Students' Hostels or living with parents and coming from the cities of above 100 thousand inhabitants. This cluster has the highest median of monthly income.

Segment II avoids extreme statements when evaluating (they prefer moderate attitudes).

Segment III shows the aversion to risk when buying advertised products they consider friends' advice. They admit that advertisements stronger affect elderly people. TV commercials are considered as the most powerful decision factor. This conclusion may come from radio listening habits. Median of 
monthly income is the lowest among all segments. Women represent $66.7 \%$ of this cluster.

Segment IV shows strong brand loyalty. Men represent $60.9 \%$ of this segment. The representatives of this cluster spend relatively less time on radio listening. More than 26\% rent a room.

Segment $\mathbf{V}$ is the least numerous. It includes the small number of respondents. On one hand they declare reluctance to advertisements but on the other hand they seek for the source of potential benefits in advertisement. Men represent $64.7 \%$ of this cluster. This cluster devotes most of its time to TV watching. The highest percentage of them are the flat owners.

Segment VI does not look for the source of future benefits. It shows the reluctance to advertisements. It devotes relatively less time to TV watching and radio listening.

Respondents of segment VII do not trust advertisements showing at the same time. Strong brand loyalty the highest percentage wish relation to other segments rents a room.

\section{Concluding remarks}

The use of segmentation variables measured on ordinal scale is relatively rare in the literature. The specific analytical tools are needed for such information. Important aspect of this study was formulation, in the methodological sense, certain segmentation procedure which implements ordinal variables as a consumer description criteria.

In the empirical study seven segments have been established. The profiles of seven segments were analysed. Moreover, this segmentation study may be regarded also as a contribution to evaluation of students' reactions as peculiar social group of advertisement receivers.

Additional result of this study is computer program, which allows computing distances between objects (see Appendix).

\section{Appendix}

The computer code in the $\mathrm{C}++$ language computing the value of measure (1) of the distance considered is available at Wroclaw University of Economics in the Dept of Econometrics and Computer Science (e-mail: abak@keii.ae.jgora.pl).

Computational algorithm of distance (1) presented below, omits details of enter and exit operations. The complete computer programme uses files in DBF format, which serve both as the data source and the result files. The Borland ${ }^{\circledR}$ $\mathrm{C} / \mathrm{C}++$ v. 4.0 compiler was used for the programming and the CodeBase++ ${ }^{\mathrm{TM}}$ v. 5.1 library procedures served as a database programming language. As the result of its application the distance matrix is generated. This matrix may be 
used in the hierarchical agglomerative methods of the classification for division of set of objects into classes. This matrix can be used also for further computations in the SPSS for Windows package.

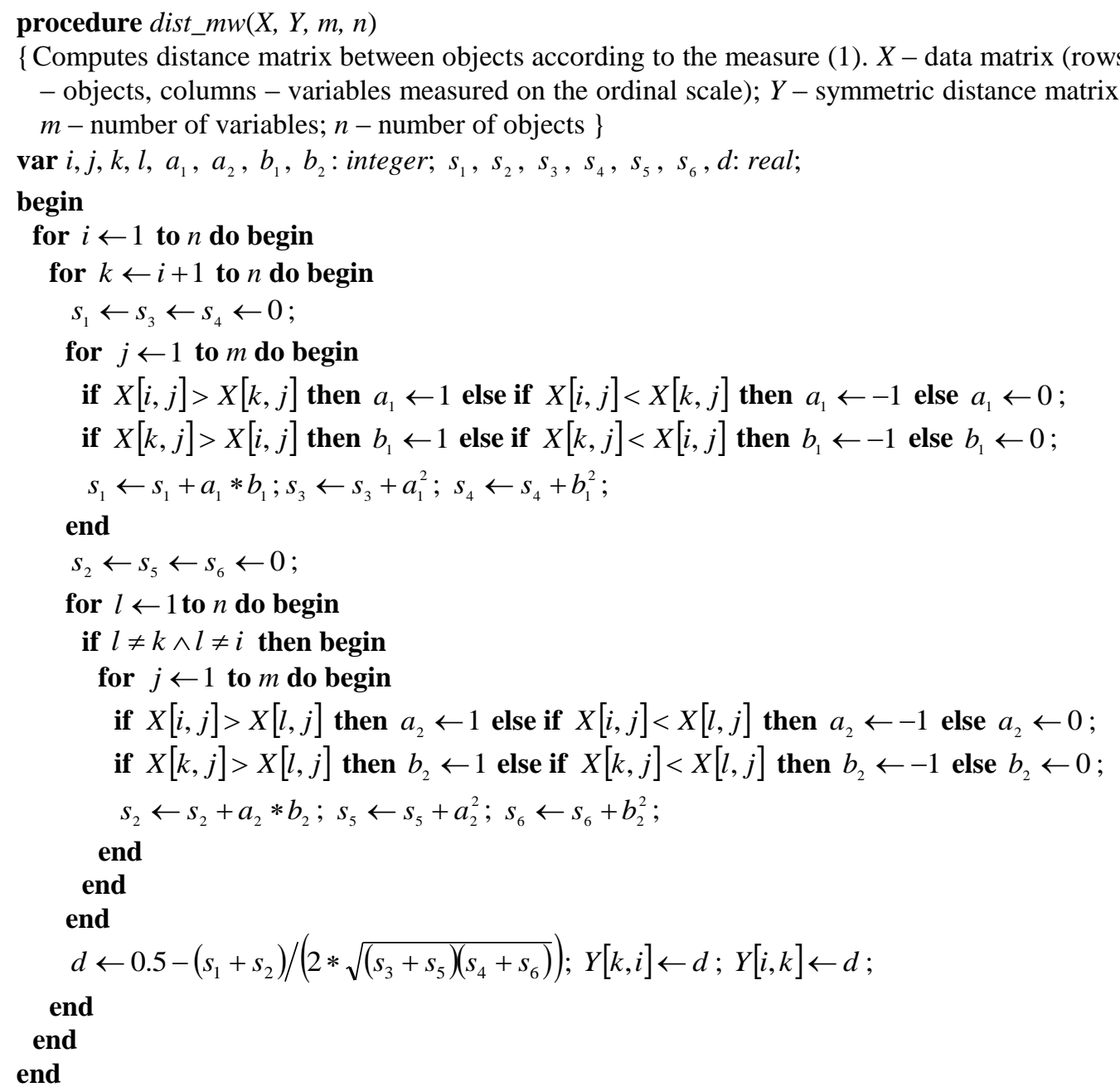

\section{References}

Anderberg, M. R. (1973). Cluster Analysis for Applications, Academic Press, New York, San Francisco, London.

Arabie, P. \& Hubert, L. (1994). Cluster Analysis in Marketing Research, in Advanced Methods of Marketing Research, Bagozzi R.P. (Ed.), Blackwell, Oxford, 160-189.

Arabie, P. \& Hubert, L. (1996). Advances in Cluster Analysis Relevant to Marketing Research, in From Data to Knowledge, Gaul, W. \& Pfeifer, D. (Eds.), Springer, 3-19. 
Beane, T. P. \& Ennis, D. M. (1987). Market Segmentation. A Review, European Journal of Marketing, 21, (5), 20-42.

Cormack, R. M. (1971). A Review of Classification (with Discussion), Journal of the Royal Statistical Society, Ser. A, (3), 321-367.

Everitt, B. S. (1974). Cluster Analysis, Heinemann, London.

Frank, R. E. \& Green, P. E. (1968). Numerical Taxonomy in Marketing Analysis: a Review Article, Journal of Marketing Research, 5, (February), 83-98.

Frank, R. E. Massy, W. F. \& Wind, Y. (1972). Market Segmentation, PrenticeHall, Englewood Cliffs.

Gordon, A.D. (1987). A Review of Hierarchical Classification, Journal of the Royal Statistical Society, Ser. A, 119-137.

Green, P. E. (1977). A New Approach to Market Segmentation, Business Horizon, 20, 61-73.

Green, P. E. \& Krieger, A. M. (1995). Alternative Approaches to Cluster-based Market Segmentation, Journal of the Market Research Society, 37, (3), 61-73.

Green, P.E., Tull, D.S. \& Albaum, G. (1988). Research for Marketing Decisions, Prentice-Hall, Englewood Cliffs.

Kaufman, L. \& Rousseeuw, P. J. (1990). Finding Groups in Data: an Introduction to Cluster Analysis, Wiley, New York.

Kendall, M. G. (1955). Rank Correlation Methods, Griffin, London.

Milligan, G. W. \& Cooper, M. C. (1985). An Examination of Procedures for Determining the Number of Clusters in a Data Set, Psychometrika, 50, (2), 159-179.

Punj, G. \& Stewart, D. W. (1983). Cluster Analysis in Marketing Research: Review and Suggestions for Application, Journal of Marketing Research, 20, (May), 134-148.

Saunders, J. A. (1980). Cluster Analysis for Market Segmentation, European Journal of Marketing, 14, (7), 422-435.

Smith, W. (1956). Product Differentiation and Market Segmentation as Alternative Marketing Strategies, Journal of Marketing, 21, 3-8.

SPSS for Windows (1997). Version 7.51, SPSS Inc., Chicago.

Walesiak, M. (1993). Statystyczna analiza wielowymiarowa $w$ badaniach marketingowych [Multivariate Statistical Analysis in Marketing Research], Wroclaw University of Economics, Research Papers No. 654.

Walesiak, M. (1996). Metody analizy danych marketingowych [Methods of Marketing Data Analysis], PWN, Warszawa.

Wind, Y. (1978). Issues and Advances in Segmentation Research, Journal of Marketing, 15, (August), 317-337. 